\title{
Turismo na Ilha de Cotijuba sob a Percepção de seus Residentes
}

\section{Silvia Helena Ribeiro Cruz'}

RESUMO: Este antigo avalia os impactos causados pelo turismo na Ilha de Cotijuba (Pará. Brasil) sob a percepção de seus residentes. Os impactos são tocalizados através de três entoques distintos: econômico, social e no meio natural, haja vista o turismo influenciar dirctamente estes aspectos no decorrer de seu desenvolvimento. Veritica-se a sensibilidade dos moradores da Ilha quanto ao incremento da atividade turística e à accitação de visitas no seu espaço de moradia.

PALAVRAS-CHAVE: Turismo; impactos; pereepção; residentes; Ilha de Cotijuba/Pará/Brasil.

ABSTRACT: This article evaluates the impact caused by tourism on the Cotijuba Island according to its residents lestmonies. The impacts is focused through three distincts leves: economic, social and the environmental, since tourism influences directly these aspects along its process of development. It also hrings out the semsihility of the residents of the island, in relation to the increase in the touristic a reception to outsiders.

NEYWORDS: Tourism; impact; perception; residents; Illa de Cotijuba/Pará/Brazil.

1. Bacharel en Turismo pela Universidade Federal do Parai, Especialista em I'lanificação Turistica pela EC:A'USP' Mestranda en 'Turismo e Lazer pela EC:A-USP. Técnicaen P'lanejamento Turistico da Companhia l'araense de Turismo. End para corresp.: Conjunto P'edro Teixeira, r. I, n. 69- Belén - PA - Brasil - 67115-000 


\section{Introdução}

\section{Considerações Teóricas}

O envolvimento das comunidades residentes em áreas turisticas no processo de desenvolvimento da atividade tem sido estudado crtensivamente nas últimas duas décadas, principalmente por pesquisadores de universidades dos Estados Unidos, Austrália, Reino Unido c Mediterrânco

Muitos estudos enfocam como os vários grupos sociais que formam unla comunidade têm reagido perante os impactos causados pelo turismo. King. Pizam c Milman (1993) investigaram a percepção dos residentes de Nadi, Fiji, em relação aos impactos sociais causados pelo turismo. Apesar de terem um ponto de vistil favorável sobre a atividade, as respostas identificaram impactos negativos $c$ positivos especílicos que, de acordo com a visão dos entrevistados, afctam a comunidade.

Ross (1992) estudou os residentes de uma cidade australiana que reconlieceram a cxistĉncia de maior impacto positivo na economia c negativo ni criminalidade.

Johnson, Snepenger \& Akis (1993) cxaminaram a percepção dos residentes sobre o desenvolvimento do turismo $\mathrm{cm}$ uma área rural de transição cconômical. Identificaram que essa percepção sobre os impactos do turismo está relacionada com o nível de atividade cconômica da comunidade c concluíram que é mais dificil quantificar os impactos ambientais do turismo do que os cconômicos.

Madrigal (1994), além de estudar a percepção dos residentes sobre os impactos do turismo, também relacionou-a com as atitudes sobre as regras governamentais no desenvolvimento de uma perspectiva cultural. Este estudo foi realizado cm duas cidades de caracteristicas diferentes: uma urbana - York/UK (Rcino Unido) c outra rural - Sedona (Estados Unidos). Nelas o desenvolvimento tem se dado de forma bastante diferente: enquanto York tem se desenvolvido como destinação turística ao longo de alguns séculos, Sedona tem vivido um rápido desenvolvimento nas duas últimas décadas.

Vários estudos identificam impactos do turismo, outros propõem modclos que tentam moderar tais impactos. Recentemente foi realizado um estudo comparativo sobre os impactos sociais do turismo nos seguintes paises selecionados: Bulgária, Hungria, Polônia, Espanha, Reino Unido, Estados Unidos c Iugosláviá: Jafari, Pizam \& Przcclawski (1990) relatam os resultados preliminares desse estudo

No Brasil há estudos sobre os impactos do turismo em comunidades receptoras analisando scus efeitos sobre a dinâmica do espaço na comunidade.

Scabra (1979) analisa o fenômeno da segunda residência, seus efeitos sobrc as modificações do espaço (preço do terreno e forma de ocupação) e suas consequïĉncias sociais na orla maritima de Santos. Araújo (1982) faz um diagnóstico do gräu de satisfação dos turistas com os recursos humanos que trabalham com turismo cm Natal. Guanziroli ( 1983 ) discutc o impacto da const rução da rodovia Rio-Santos no desenvolvimento da região de Angra dos Reis, através da análise histórica das transformações ocorridas com a int rodução do turismo na região: o caso da Fazcnda de Santa Rita do Braculyy. Lago (1983) analisa as consequîencias do impacto da urbanização/industrialização sobre a organização de uma comunidade agricolapesqucira c as transformações na forma de ocupação de mão-de-obra. Este cstudo de caso foi realizado na comunidade de Canaviciras, Ilha de Santa Catarina (SC) que se transformou rapidamente cm balneário, cujos habitantes viviam da lavoura e pesca num passado recentc.

Como explicado anteriormente, há iniciativas de análise dos impactos decorrentes do turismo $\mathrm{cm}$ uma comunidade, entretanto, face à rápida cxpansão deste segmento no Brasil, principalmente em árcas naturais, ć necessário que esses estudos sejam realizados de forma sistemática com objetivo de prever possiveis impactos ou atć mesmo mitigar os impactos negativos identificados nos estudos.

Reis (1993) realizou um estudo sobre o desenvolvimento do turismo na Ill a de Cotijuba (PA), onde entrevistou 4 () residentes com objetivo de traçar o perfil dos moradores da Ilha, não abordando, portanto, a questão dos impactos de forma específica.

A metodologia de campo seguiu os princípios básicos da escala de atitudes Linkert, para identificação da percepção. O questionário aplicado foi bascado nos instrumentos utilizados por pesquisadores na investigação sobre a percepção dos residentes de comunidades turísticas nos Estados Unidos e no Pacífico, sendo adequados às peculiaridades da ilha.

A aplicação dos questionários deu-se através de entrevistas dirctas. Do universo de 2.80() residentes foi retirada uma amostra de 80 residentes, escolhidos aleatoriamente. O crro admissivel para o cálculo do tamanho amostral foi de $5 \%$ admitindo-se uma probabilidade de confíança de $95 \%$. Para maior subsídio à pesquisa, realizaram-se entrevistas através de depoimentos de história de vida de três moradores mais antigos, que relataram o processo de ocupação do presídio na Ilha c a relação entre este c a comunidade.

Os moradores foram entrevistados cm suas casas, não havendo procedimento preestabelecido para escolha de suas residências. Entretanto, em função de ser uma área extensa, as casas encontram-se concentradas principalmente em três vias, sendo estes pontos considerados referências para a pesquisa, sem deivar de entrevistar áreas mais distantes, como as residencias próximas às praias c áreas agricolas. Os entrevistados deveriam ter no mínimo 18 anos completos, independente do sexo. A coleta de dados foi realizada cm duasetapas, a primeira em janeiro e a segunda cm feverciro de 1995

\section{Turismo em Cotijubo}

A llha de Cotijuba faz parte do arquipélago situado na baía de Marajó fazendo parte da Grande Bclém (Pará), distando desta $33 \mathrm{~km}$. Possui uma árca de aproximadamente $107 \mathrm{~km}^{2}$, limitando-se a Norte e Oeste com a baia do Marajó, a 
Leste com a baía de Santo Antônio e a Sul com as Ilhas de Paquetá c Jutuba. A temperatura média anual ć de $27,9^{\circ} \mathrm{com}$ a média das máximas anuais atingindo $31,8^{\circ}$ c a média das mínimas chegando a $22,3^{\circ}$. O clima de Cotijuba ć o comum da Amazônia Equatorial - superúmido. Nos meses de dezembro a março ć o período de maior incidência pluviomćtrica. A vegetação predominante ć de palmáceas, destacando-se o açaizeiro, que representa quase $96 \%$ da cobertura vegctal, c outras espécics frutiferas como as manguciras e taperabazciros, que permitem a colheita durante o ano todo na forma cxtrativista. Classificada, segundo critérios genćticos de Jacques Huber, como uma ilha antiga, Cotijuba ć formada de depósitos arcnosos c argilosos, com uma ou mais camadas de arenito, apresentando constituição semelhante à da terra firme continental, sendo seu solo caracterizado como de várzea praiana (O Libcral, 1991; Reis, 1992).

Historicamente. a Ilha de Cotijuba representa o marco para o inicio do sistema penitenciário do Estado do Pará, pois abrigou durante aproximadamente duas décadas o presídio para infratores altamente perigosos à sociedade. Após a desativação do presídio, o prédio de arquitetura não-definida, mas com caráter imponente, foi abandonado, permanecendo na Ilha alguns cs-presidiários já cm liberdade $\mathrm{c}$ alguns funcionários do antigo presídio que ali fixaram residência c formaram familias. Atualmente, as ruinas do prédio representam o monumento que marcou a história de Cotijuba.

A atividade econômica que começou a ser praticada por seus moradores a partir de 1970 foi principalmente a agricultura, trazida por um grupo de japoneses que ali chegaram. A partir deste periodo, a Ilha de Cotijuba passou a ser o principal abastecedor de hortaliças para os mercados de Belém. No final da década de 8()$, 0$ turismo começou a chegar cm Cotijuba, sendo atualmente considerado como a principal fonte de renda para seus residentes, depois da agricultura.

A Ilha ć circundada por um "colar" de praias com aproximadamente $20 \mathrm{~km}$ de c.xtensão. Possui também floresta, rios, igarapés, que juntos formam um quadro natural bem diversificado.

Atualmente, Cotijuba dispõe de modesta infra-estrutura hoteleira para 0 turismo e serviços de alimentação, oferecendo alternativas para seus visitantes. além de infra-estrutura básica, como saúde c água. Não há energia elétrica, apenas uso de velas e lamparinas. Em função do fluxo constante de visitantes que se deslocam para a Ilha, a Prefeitura Municipal de Belém implantou um sistella de transporte mais adequado, assim como está propondo a claboração de um plano diretor para a Ilha, visando o planejamento de suas atividades.

Segundo dados da Paratur de 1994, a permanência média dos visitantes que pernoitam em Cotijuba ć de dois dias. Mas a maioria fica apenas um dia c retorna para Belém. Ainda é importante ressaltar que há os que adquiriram lotes de terras c possuem segunda residência para férias ou para passar o final de semana na llha.

\section{Principais Resultados}

Dos entrevistados, $60 \%$ não nasceram na llha, confinmando a característica peculiar da região, que ć a constante mobilidade deseus residentes em virtude de estarem sempre procurando melhores condições de vida. O nível de escolaridade é baixo - 56,2\% destrevistados possucm o $1^{\circ}$ grau incompleto Estefato relaciona-se à não-cxistência de doș enturer educional na Ilha, que possui uma escola estadual de $1^{\circ}$ grau. infra-estnutura do setor educacional ná que a Ilha não ć habitada por jovens, pois estes deslocam-se para o centro urbano mais próximo cm busca de melhores oportunidades.

O comércio ligado ao turismo ć atualmente o segundo recurso profissional para os moradores. representando um percentual de 13,7\%, sendo que a agricultura pantinua liderando o mercado com $16,3 \%$, reafirmando a sua tradição nesta atividade.

É importante ressaltar que, de acordo com depoimentos, o turismo vem contribuindo para diversificar o quadro de alternativas profissionais, pois além do comćrcio de alimentos e bebidas, também intensificou o meio de transporte fluvial, absorvendo pessoal para auxiliar na venda de passagens. O turismo também está intensificando o mercado informal da economia, pois vários moradores aproveitam o fluxo intenso de visitantes e vendem frutas, verduras, doces e iguarias diversas cm suas casas ou cm pontos estratćgicos da Ilha.

TABELA 1 - OPINIĀO DOS RESIDENTES DA ILHA DE COTIJUBA SOBRE A PRESENÇA DE TURISTAS

\begin{tabular}{|c|c|c|c|c|c|c|}
\hline $\begin{array}{l}\text { Opinião } \\
\text { Etaixa }\end{array}$ & $\begin{array}{l}\text { Extre- } \\
\text { mamente } \\
\text { contrário }\end{array}$ & $\begin{array}{l}\text { Pouca } \\
\text { oposição }\end{array}$ & $\begin{array}{c}\text { Nem a } \\
\text { favor } \\
\text { nem } \\
\text { contra }\end{array}$ & $\begin{array}{c}\text { Pouco } \\
\text { favorável }\end{array}$ & $\begin{array}{l}\text { Extre- } \\
\text { mamente } \\
\text { favorável }\end{array}$ & Total \\
\hline menos de 20 & 1 & 2 & - & 1 & 4 & 8 \\
\hline 20 a 29 & - & 3 & 2 & 1 & 8 & 14 \\
\hline 30 a 39 & - & 3 & 2 & 2 & 14 & 21 \\
\hline 40 a 49 & - & 3 & 6 & - & 12 & 21 \\
\hline mais de 49 & - & 1 & 3 & 4 & 8 & 16 \\
\hline Total & 1 & 12 & 13 & 8 & 46 & 80 \\
\hline $\begin{array}{c}\text { Participação } \\
\%\end{array}$ & 1,3 & 15 & 16,2 & 10 & 57.5 & 100 \\
\hline
\end{tabular}

Fonte: Pesquisa na llha de Cotijuba - Fev./95 
TABELA 3 - OPINIÃO DOS RESIDENTES NA ILHA DE COTIJUBA QUANTO AOS

De acordo com o que demonstra a Tabela 1 , quanto à opinião dos residentes da Ilha sobre a presença dos turistas, $57,5 \%$ são extremamente favoráveis à presença dos turistas, c um percentual mínimo de 1,3\% é extremamente contrário aos turistas; $41,2 \%$ ficou entre pouca oposição à presença de turistas, nem a favor nem contra e pouco favorável.

Desse modo considera-se que a comunidade de Cotijuba está no momento de euforia da chegada dos visitantes. Caso este fluxo não seja organizado e controlado poderá levar ao estágio de repulsa, principalmente porque já se observoı uma pequena resistência quanto aos visitantes na Ilha.

\section{TABELA 2 - CONTATO DOS RESIDENTES COM OS TURISTAS}

\begin{tabular}{l|l|l}
\hline \multicolumn{1}{c|}{ Tipo de Contato } & Freq.Abs. & (\%) \\
\hline Não tem nenhum contato & 29 & 36,3 \\
Tem algum contato & 37 & 46,2 \\
Tem contato constante & 14 & 17,5 \\
\hline Total & 80 & 100 \\
\hline
\end{tabular}

Fonte: Pesquisa na llha de Cotijuba - Fev./95

Na Tabela 2 observa-se que os residentes sempre estão em contato com os turistas, seja constante ou não. Na escala apresentada, o item "tem algum contato" recebeu maior freqüência, com 46,2\%. No item "não tem nenhum contato"a frequiência foi de $36,3 \% \mathrm{c}$ "tem contato constante" ficou com $17,5 \%$, demonstrando que este é feito com um pequeno número de residentes. É importante observar que o turismo está envolvendo, mesmo que de forma lenta, a comunidade no sel processo de desenvolvimento.

\section{Impactos Econômicos}

Pelos dados da Tabela 3, observa-se que os moradores da Ilha de Cotijuba acreditam nos benefícios econômicos do Turismo: concordam que o mesmo esta atraindo mais investimentos, empregos e contribuindo para a melhoria do nível de vida

Entretanto, 35,5\% dos residentes discordam plenamente que com o turismo os preços aumentaram, $22,8 \%$ concordam plenamente que houve aumento dos preços, e $20,2 \%$ concordam em parte, havendo divergência de opiniões. Na estrutura da economia local, o turismo está beneficiando um pequeno número do moradores, com 55,1\% concordando plenamente, fato este que demonstra uma percepção mais crítica em relação à atividade, pois os custos c benefícios são apontados de forma clara.
TABELA 3- OPINIAO DOS RESIDENTES OURIMO TRAZ PARA A ILHA

\begin{tabular}{l|c|c|c|c|c|c|c|c|c|c}
\hline Opiniäo & \multicolumn{2}{|c|}{$\begin{array}{c}\text { Concordo } \\
\text { plenamente }\end{array}$} & \multicolumn{2}{c|}{$\begin{array}{c}\text { Concordo } \\
\text { em parte }\end{array}$} & \multicolumn{2}{|c|}{ Não sei } & \multicolumn{2}{c|}{$\begin{array}{c}\text { Discordo } \\
\text { em parte }\end{array}$} & \multicolumn{2}{c}{$\begin{array}{c}\text { Discordo } \\
\text { plenamente }\end{array}$} \\
\hline Itens & Abs. & $\%$ & Abs. & $\%$ & Abs. & $\%$ & Abs. & $\%$ & Abs. & $\%$ \\
\hline $\begin{array}{l}\text { O turismo traz } \\
\text { emprego }\end{array}$ & 38 & 48,4 & 19 & 24,0 & 4 & 5,1 & 4 & 5,1 & 14 & 17,7 \\
$\begin{array}{l}\text { O turismo atrai } \\
\text { investimentos }\end{array}$ & 43 & 60,6 & 19 & 26,8 & 4 & 5,6 & 3 & 4,2 & 2 & 2,8 \\
e gastos & & & & & & & & & & \\
$\begin{array}{l}\text { Nosso nivel de } \\
\text { vida cresceu }\end{array}$ & 34 & 43,1 & 33 & 41,8 & 2 & 2,5 & 5 & 6,3 & 5 & 6,3 \\
$\begin{array}{l}\text { Os preços } \\
\text { aumentaram } \\
\text { com o turismo }\end{array}$ & 18 & 22,8 & 16 & 20,2 & 1 & 1,3 & 16 & 20,2 & 28 & 35,5 \\
$\begin{array}{l}\text { O turismo } \\
\text { beneficia um } \\
\text { pequeno } n \text {. de } \\
\text { moradores }\end{array}$ & 43 & 55,1 & 7 & 9 & 2 & 2,6 & 12 & 15,4 & 14 & 17,9 \\
\hline
\end{tabular}

Fonte: Pesquisa na liha de Cotijuba - Fev.195

\section{Impactos Sociais}

Os itens propostos para avaliação foram baseados $\mathrm{cm}$ uma visão globalizante dos fatores que interferem no complexo social da Ilha, objetivando captar a dos fatorcs que in tempo identificar suas relações internas

e influências que estão causando nos segmentos sociais.

A comunidade da Ilha de Cotijuba tem a percepção de que o tus de recreainterferindo diretamente $\mathrm{em}$ sulas rclaçōes sociais, seja nas alternativas de recrila ção, infra-estrutura básica ou segurança e ainda nas formas de convivencia familiar c comunitária.

A atividade turística tem proporcionado alternativas de recreação que antes ão existiam, como as festas, jogos de futcbol ou até mesmo o fato de poderem conversar com outras pessoas ou vê-las passando $\mathrm{cm}$ frente às suas casas. Entretan10, as crianças ainda são tolhidas dessa alternativa, pois com o turismo suas aspirozos a madaram, passando a cxigir outras altcrnativas de aspirações c a de scus pais mudaram, passando a cxigir on nos quintais e ruas: recreação que não scja apenas a praia ou brincadeiras livres nos quintais e ruas: estão almejando praças c parques para as crianças. percepção de seus moradores e ao mesmo mentos sociais. 


\begin{tabular}{|c|c|c|c|c|c|c|c|c|c|c|}
\hline \multirow[t]{2}{*}{ Opiniāo } & \multicolumn{2}{|c|}{$\begin{array}{l}\text { Concordo } \\
\text { plenamente }\end{array}$} & \multicolumn{2}{|c|}{$\begin{array}{l}\text { Concordo } \\
\text { em parte }\end{array}$} & \multicolumn{2}{|c|}{ Nāo sei } & \multicolumn{2}{|c|}{$\begin{array}{l}\text { Discordo } \\
\text { em parte }\end{array}$} & \multicolumn{2}{|c|}{$\begin{array}{l}\text { Discordo } \\
\text { plenamente }\end{array}$} \\
\hline & Abs. & $\%$ & Abs. & $\%$ & Abs. & $\%$ & Abs. & $\%$ & Abs. & $\%$ \\
\hline $\begin{array}{l}\text { O turismo proporciona alternativas de } \\
\text { recreação }\end{array}$ & 32 & 47,1 & 20 & 29,4 & 1 & 1,5 & 2 & 2,9 & 13 & 19,1 \\
\hline O turismo modifica os costumes culturais & 21 & 33,3 & 20 & 31,7 & - & - & 7 & 11,1 & 15 & 23,9 \\
\hline $\begin{array}{l}\text { O turismo tem melhorado o saneamento } \\
\text { básico e o abastecimento de água }\end{array}$ & 5 & 8,8 & 20 & 35,1 & 1 & 1,8 & 4 & 7,0 & 27 & 43,7 \\
\hline $\begin{array}{l}\text { O transporte de acesso melhorou em função } \\
\text { do turismo }\end{array}$ & 71 & 89,9 & 6 & 7,6 & - & - & 1 & 1 & 1 & 1,3 \\
\hline $\begin{array}{l}\text { O sistema de saúde melhorou em função do } \\
\text { turismo }\end{array}$ & 41 & 52,6 & 19 & 24,4 & 2 & 2,6 & 8 & 10 & 8 & 10,2 \\
\hline $\begin{array}{l}\text { O sistema de energia elétrica melhorou em } \\
\text { função do turismo }\end{array}$ & 34 & 2,4 & - & - & - & - & 1 & 2,4 & 39 & 95,2 \\
\hline $\begin{array}{l}\text { O turismo incentivou o aumento das } \\
\text { atividades culturais produzidas pelos } \\
\text { residentes (artes, folclore) }\end{array}$ & 3 & 8,3 & 11 & 30,6 & - & - & 5 & 13,9 & 17 & 47,2 \\
\hline $\begin{array}{l}\text { O turismo tem contribuido para o crescimento } \\
\text { da cirminalidade }\end{array}$ & 36 & 45,6 & 13 & 16,4 & - & - & 7 & 8,9 & 23 & 29,1 \\
\hline $\begin{array}{l}\text { A llha seria melhor se os turistas não viessem } \\
\text { aqui }\end{array}$ & 11 & 14,3 & 7 & 9.1 & 5 & 6.5 & 11 & 14,3 & 43 & 55,8 \\
\hline
\end{tabular}

\section{TABELA 4-(CONTINUAÇAO)}

\begin{tabular}{|c|c|c|c|c|c|c|c|c|c|c|}
\hline \multirow[b]{2}{*}{ Itens } & \multicolumn{2}{|c|}{$\begin{array}{l}\text { Concordo } \\
\text { plenamente }\end{array}$} & \multicolumn{2}{|c|}{$\begin{array}{l}\text { Concordo } \\
\text { em parte }\end{array}$} & \multicolumn{2}{|c|}{ Não sei } & \multicolumn{2}{|c|}{$\begin{array}{l}\text { Discordo } \\
\text { em parte }\end{array}$} & \multicolumn{2}{|c|}{$\begin{array}{c}\text { Discordo } \\
\text { plenamente }\end{array}$} \\
\hline & Abs. & $\%$ & Abs. & $\%$ & Abs. & $\%$ & Abs. & $\%$ & Abs. & $\%$ \\
\hline $\begin{array}{l}\text { O crescimento do turismo tem aumentado o } \\
\text { preço da propriedade e está além do poder } \\
\text { aquisitivo de residentes mais jovens }\end{array}$ & 42 & 53,1 & 17 & 21,5 & 7 & 8,9 & 6 & 7,6 & 7 & 8,9 \\
\hline $\begin{array}{l}\text { Os turistas que vêm para a llha geralmente } \\
\text { têm pouca consideração com a população } \\
\text { local }\end{array}$ & 18 & 22,8 & 29 & 36,7 & 2 & 2,5 & 13 & 16,5 & 17 & 21.5 \\
\hline $\begin{array}{l}\text { Em função do turismo a llha tem bons } \\
\text { restaurantes }\end{array}$ & 33 & 46,5 & 18 & 25,4 & 4 & 5,6 & 5 & 7,00 & 11 & 15,5 \\
\hline $\begin{array}{l}\text { Os residentes sofrem por morarem em áreas } \\
\text { turisticas }\end{array}$ & 8 & 10,5 & 15 & 19,7 & 5 & 6,6 & 5 & 6,60 & 43 & 56,6 \\
\hline $\begin{array}{l}\text { As autoridades não consideram a opinião dos } \\
\text { residentes quando decidem sobre o futuro da } \\
\text { Ilha }\end{array}$ & 26 & 36,2 & 14 & 19,4 & 1 & 1,4 & 14 & 19,4 & 17 & 23,6 \\
\hline Com o turismo a produção agrícola aumentou & 43 & 54,4 & 21 & 26,6 & 3 & 3,8 & 3 & 3,8 & 9 & 11,4 \\
\hline $\begin{array}{l}\text { Com o turismo a produção pesqueira } \\
\text { aumentou }\end{array}$ & 13 & 17,1 & 14 & 18,4 & 11 & 14,5 & 8 & 1,5 & 30 & 39,5 \\
\hline
\end{tabular}


Para os residentes há mudanças nos costumes culturais da Ilha. pois os hábitos e costumes originais estão desaparecendo com a chegada dos visitantes

Apesar de o turismo exigir um abastecimento de água estruturado saneamento básico apropriado às suas instalações. a Ilha de Cotijuba não possui cs sistema. continuando com fossas sem tubulação. Não existe esgoto sanitíro comunitário e a captação de água é feita através de poços simples suprindo as necessidades de alimentação e banho da comunidade.

Desse modo. para $43,7 \%$ dos residentes o turismo não tem contribuído para melhorar o sancamento básico nem o abastecimento de água.

O transporte de acesso até novembro de $199+$ cra feito por pequenals cmbarcações com capacidade para aproximadamente 25 pessoas. sendo monopolizado por 30 barqueiros, que dobravam os preços das passagens nos finais de semana, impedindo o deslocamento dos moradores, pois estes com baixo poder aquisiti๋ não podiam pagar o preço cobrado. Os barcos também não tinham horários estabelecidos de saída e chegada.

Entretanto. a Prefeitura Municipal de Belém, para suprir as lacunas existentes no transporte de acesso à Illha, implantou o sistema regular de barcos com capacidade para $4(0)$ pessoas, obedecendo horários definidos. inclusive nos finais de semana, scguindo o preço do transporte colctivo de Belém. objetivando com isso bencficiar o lurista e o morador da Ilha. Assim 89.8\% concordam plenamente que o transporte para a Ilha melhorou.

Os senviços de saúde também receberam melhorias. O único Posto de Saúde da Ilha foi equipado com matcriais e equipamentos novos. formando un quadro médico e odontológico para atendimento dos moradores e visitantes. incluindo plantões nos finais de semana.

A encrgia clétrica é inexistente. c mesmo com o turismo na illa ainda não houre iniciativas para implantação desse sistema.

O turismo não incentivou as atividades culturais, principalmente porque mesmo antes de o turismo chegar cm Cotijuba. as manifestações culturais. representadas por grupos folclóricos. artesanato ou outra manifestaç̃o não cri presente na vida da comunidade. Observou-se que as atividades culturais normalmente aproveitadas pelo turismo como oferta. ou componente de seu desenrolimento, não é elemento dos atrativos de Cotijuba.

Com cssa visão crítica. os moradores têm a clara percepção de que com 0 turismo a criminalidade aumentou significativamente. principalmente após : implantação do sistema regular de transporte. Os principais delitos são porte de tóxicos e brigas após ingestão de álcool.

Os moradores discordam plenamente do item "a Ilha seria melhor se os turistas não viessem aqui". demonstrando assim sua sensibilidade cm relaç̃o a atividade turístical.

A especulação imobiliária começou a fazer parte das relações sociais dial comunidade de Cotijuba, os preços dos terrenos aumentaram em função da procuria

Para 22,8\% dos moradores os turistas não têm consideração com a população local, principalmente pelo fato de não haver respeito pelo espaço de moradia.
Porém, 56,6\% dos entrevistados discordam plenamente que os residentes sofrem por morarem $\mathrm{cm}$ áreas turísticas.

Observou-se que entre os moradores da Ilha há um grupo de pessoas resistentes quanto ao fluxo turístico, pois sentem-se incomodados com a falta de respeito demonstrada pelos visitantes na relação comunidade e turista, consequiência de um turismo não-planejado que está sendo implementado.

Com o turismo surgiram restaurantes e bares até então inexistentes, aquecendo o comércio e criando empregos seja direta ou indiretamente.

A Ilha de Cotijuba faz parte da administração da Prefeitura Municipal de Belém, entretanto as autoridades, quando decidem sobre o destino da Ilha, não consultam os moradores, de acordo com $36,2 \%$ dos entrevistados.

A produção agrícola sofreu alterações com o turismo, pois a Prefeitura Municipal de Belém incentivou essa atividade com a implantação de projetos de cultivo de hortaliças, devolvendo aos agricultores a oportunidade de produzir. visando o fluxo turístico e a exportação. Este fato foi acordado por $54,4 \%$ dos entrevistados, que concordaram plenamente com o aumento da produção.

Na produção pesqueira não se observou alteração, confirmando a não- tradição da Ilha nessa atividade, com 39,5\% dos entrevistados discordando plenamente.

\section{Impactos no Meio Natural}

O turismo não está respondendo aos anscios de conservação ambiental, pois $37 \%$ dos residentes discordaram plenamente quanto ao incentivo para restauração de monumentos históricos ${ }^{2}$ e recursos naturais; $35,6 \%$ concordaram em parte que o turismo tem proporcionado a criação de áreas abertas como parques e áreas recreativas e $30,5 \%$ discordaram plenamente, scndo a Ilha desprovida desses equipamentos de lazer.

É lamentável, mas em função da falta de planejamento do turismo $\mathrm{cm}$ Cotijuba, a atividade tem contribuído para o acúmulo de lixo nas praias, rios $\mathrm{c}$ igarapés, dado csse confirmado por $39,7 \%$ dos entrevistados.

Além do grande fluxo de visitantes que chegam à Cotijuba para finais de semana, a Ilha está sendo utilizada como local de segunda residência para aqueles que adquiriram lotes e construíram casas. Mesmo assim, 34,2\% dos residentes acham que o turismo não tem provocado desmatamentos, pois ao sentirem esta ameaça, os residentes organizaram-se e fundaram o Grupo Ecológico da Ilha de Cotijuba - Ecotijuba, buscando orientação e apoio junto ao Instituto Brasileiro de Meio Ambiente - Ibama para ordenar e regular o uso dos ambientes naturais. como areas de loteamentos, assim como proibir a retirada de pedras e arcia das praias.

Quando questionados sobre o desaparecimento de animais existentes, em função do turismo, 46,5\% discordaram plenamente desse item. Para os residentes não houve alteração que prejudicasse a existência de animais endêmicos.

2. Há dois prédios históricos na Ilha 
Com relação à devastação de ánores frutíferas, plantas, gramíncas c vegetação $\mathrm{em}$ geral, $53.8 \%$ discordaram plenamente do desaparecimento dessa vegelação. Esclareceram ainda que o fluxo turístico da Ilha ainda não provocou a diminuição das frutas naturais, como: laperebá, manga, cupuaçu c coco.

\section{Conclusāo}

O resultado dessa investigação mostra que os residentes da Ilha de Cotijuba „ão são contrários à cxpansão do turismo, favorecendo o seu desenvolvimento.

Demonstraram uma percepção positiva quanto ao turista. Entretanto, apontaram alguns pontos negativos específicos surgidos na llha com o processo da chegada dos turistas, como o uso de drogas, brigas, não-pagamento de consumo c outros vandalismos, inclusive roubo de residências. Os cfeitos positivos foram principalmente quanto ao aspecto cconômico, refercnte à criação de alternativas para aumentar a renda familiar através do comércio, conseqüentemente melhores condições de vida para a comunidade, como a melhoria de acesso à saúde.

Ainda ć importante ressaltar que o turismo contribuiu para a organização comunitária, objctivando a conscrvação ambiental através da criação de um grupo especifico de moradores que começaram a fiscalizar as ações das pessoas quanto às agressões ambicntais. reccbendo apoio legal do lbama.

Tcorias afirmam que os residentes suportam o turismo principalmente $\mathrm{cm}$ função de seus bencficios cconômicos, entretanto os resultados também demonstram que os mesmos estão abertos para discutir os impactos negativos causados pela atividade

O turismo, assim como pode trazer impactos positivos, lambém provoca impactos negativos sobre determinada comunidade, c esta ć capaz de diferenciar estes limitcs, chegando a impor regras para o uso de seus recursos.

Porćm, a Ilha de Cotijuba ainda sofre as consequienncias administrativas $\mathrm{c}$ políticas de uma gestão municipal que não conseguiu definir suas prioridades de desenvolvimento, mas apesar disso a comunidade clegcu o turismo como a segunda alternativa de meio de trabalho para seus moradores.

Para concluir, observou-se que a Illha de Cotijuba, além de possuir diversificação de recursos para o seu aproveitamento turístico, possui ainda a cumplicidade de seus moradores quanto ao uso da Ilha para o turismo, pois a percepção de sua cominidade demonstra o seu entendimento quanto aos benefícios que a atividade pode trazer, assim como identifica os impactos negativos originados com o seu processo de descnvolvimento. Evidenciaram-se ainda regras e limites impostos pelos residentes em alguns momentos da implementação do turismo.

Há porém urgência quanto à sistematização da atividade na Ilha, cxigindo definições cmergentes dos orgãos competentes quanto às diretrizes que deicm ser tomadas para o fomento do turismo cm Cotijuba, sem deixar de cnvolver a comunidade no processo de decisão c opcracionalização do turismo. 


\section{Referências Bibliográficas} ARAÜJO, Matilde Medeiros de. 1982. Uma análise das percep̧̧öes dos turistas sobre os recursos humutnos do setor
turistico de Natal: Natal: UIRN. 101 p. Dissertação de Mestrado.

GUANZIROLI, Carlos Enrique. 1983. Contnbuição à reflexão sobre o processo de produção de um espuç̧, reģional - caso de Angra dos Reis. Rio de Janeiro: COPPE - UFRJ. 338p. Dissertação de Mestrado.

JOH NSON, Jem;, SNEPENGER, Darid S AKIS, Scrgin. 1993. Residents perceptions of tourism develupm:n: Innul. of Tourism Research. Menomonie.

O LIBERAL. 1991. Cotijuba fadada a virar balneário. Belém, 31 set.

KERINGER, Fred N. 1973. Foundations of behavioral research. 2 ed. USA: Holt Ripehart and IVinston

KING, Brian; PIZAM, Abraham \& MILMAN, Ady: 1993. Social impacts of tourism. Host perceptions. Annuls of Tourism Research. Menomonie, n. 20, p. 650-55.

JAFARI, J,; PIZAM, \& PRZEDLAIVSKI, 1990

KRIPPENDORF, Jost. 1991. The Holidav Makers.

LAGO, Mara Coelho de Souza 1983. Memória de uma comunidade que se transforma. De localidade agricolapesqueira a balnecirio. Florianópolis: UFSC. Hp. Dissertação de Mestrado.

MADRIGAL, Robert. 1994. Residents perceptions and the role of government. Annals of Jourism Research. 21: 80-102

PARATUR. Companhia Paraense de Turismo. 1994. Boletim de Ocorréncia de llóspedes.

REIS, Luis \& PANTOJA, Lui\%. 1992. Projeto de desemolvimento do turismo nallha de Cotijuba (uma visão ecológica). Belém: UTPA (Trabalho de Conclusão de Curso)

REJOIVSKI, Mirian 1993. Pesquisa acadèmica em turismo no Brasil (1975 a 1992). Configuração e sistematizaçãe documental. São Paulo: ECA-USP. 885 p. Tese de Doutorado.

ROSS, Gilenn F. Resident perceptions of the impact of tourism on an Australian city. Journal of Travel Rescurch, v. 30 , n. 4. p. 13-7.

SE:ABRA, Odette Carvalho de Lima. 1979. A muralha que cerca o mar. Una modalidade de uso do solo urbano. São Paulo: FFLCH-USP. 91 p. Dissertação de Mestrado 